\title{
Assessing cubicle dimensions for finishing bulls based on animal behaviour and cleanliness
}

\author{
L. Gygax ${ }^{1 \dagger}$, H. Schulze Westerath ${ }^{1}$, J. Kuhlicke', B. Wechsler ${ }^{1}$ and C. Mayer ${ }^{2}$ \\ ${ }^{1}$ Centre for Proper Housing of Ruminants and Pigs, Swiss Federal Veterinary Office, Agroscope FAT Tänikon, 8356 \\ Ettenhausen, Switzerland \\ 2Institute for Animal Welfare and Animal Husbandry, Federal Agricultural Research Centre, Dörnbergstrasse 25 and 27, 29223 \\ Celle, Germany
}

${ }^{\dagger}$ E-mail: lorenz.gygax@fat.admin.ch

\begin{abstract}
Finishing bulls need increasingly large cubicles throughout their growth, and optimal cubicle dimensions may differ from those used for dairy cows. The space requirements of finishing bulls was investigated by observing standing-up and lying-down behaviour, lying duration and number of lying bouts, as well as the cleanliness of cubicles and animals before and after increasing cubicle size at four different points in time. Lying area in the cubicles measured $120 \times 70 \mathrm{~cm}$ at the start and $185 \times 110 \mathrm{~cm}$ at the end of the finishing period (approx. at 160 and $550 \mathrm{~kg}$, respectively). Twenty animals kept in four groups were observed at weights of approximately 220,330, 380 and $500 \mathrm{~kg}$ before and after cubicle dimensions were increased. The proportion of standing-up events with more than one head lunge decreased with enlargement of the cubicles $(\mathrm{P}=0.01)$. As cubicle size increased, bulls hit the partition rails less on standing up, except at $220 \mathrm{~kg}$ weight where the pattern was inverted (interaction: $\mathrm{P}=0.001$ ). Partitions were also hit less on lying down as cubicle size increased, except at $220 \mathrm{~kg}$ weight with an inverse pattern (interaction: $\mathrm{P}=0.01$ ). The number of exploratory head sweeps before lying down did not change with cubicle enlargement $(\mathrm{P}>0.5)$. Bulls slipped more often with cubicle enlargement, except at $380 \mathrm{~kg}$ where the difference was inverted (interaction: $\mathrm{P}=0.03$ ). They never fell and never turned around in the cubicles. In general, both animals and cubicles were very clean. On average, lying duration decreased $(\mathrm{P}<0.01)$ while the number of lying bouts tended to increase $(\mathrm{P}=0.052)$ with enlargement of the cubicles but the absolute differences were small. Consequently at each point in time, the smaller cubicles still seemed to provide sufficient lying space for the bulls. If the impacts with the partitions were minor and did not represent a serious welfare concern, as suggested by qualitative observations, the cubicle dimensions used could be considered suitable for housing the type of finishing bulls used in this study.
\end{abstract}

Keywords: behaviour, bulls, cubicles, hygiene, loose housing.

\section{Introduction}

Cubicles are widely used for housing dairy cows. In recent years, they have also been introduced and tested for finishing bulls (Schulze Westerath et al., 2003, 2004 and 2005; Meier et al., 2004). If equipped with soft lying mats, this alternative housing system can provide a more comfortable lying area for finishing bulls than fully slatted pens, without the need for large quantities of litter as in deep-bedded straw pens. Although hard lying areas with a rough surface have been shown to have negative effects on behaviour and leg injuries in finishing bulls (Ruis-Heutinck et al., 2000; Lowe et al., 2001; Mayer et al., 2002), cubicles with straw bedding are not recommended for bulls because the animals would wet the ground when urinating while standing in the cubicles.

One major issue in cubicle design is size. If cubicles are too small, cattle show changes in their lying behaviour. Hörning and Tost (2002) found changes in lying duration and in lying- down and standing-up movements in dairy cows when cubicle size varied from about $2.3 \mathrm{~m}$ to $2.5 \mathrm{~m}$ in length, and from about $1.1 \mathrm{~m}$ to $1.2 \mathrm{~m}$ in width. In cubicles measuring $229 \mathrm{~cm}$ long by $112 \mathrm{~cm}$ wide as opposed to larger cubicles measuring $274 \mathrm{~cm}$ long by $132 \mathrm{~cm}$ wide, dairy cows spent less time lying and more time standing with only the front hooves on the lying surface (Tucker et al., 2004). On the other hand, if cubicles are too large, the lying surface may get dirty (Bickert, 1999; Tucker et al., 2004), which could adversely affect skin and udder health as well as milk quality in dairy cattle.

There are different approaches to defining cubicle size for cattle. Firstly, there is the trial-and-error approach, in which cubicles are built to a size based on an intuitive understanding of how much space cattle need for lying, lying down and standing up. Secondly, several attempts have been made to 


\section{Gygax, Schulze Westerath, Kuhlicke, Wechsler and Mayer}

base cubicle dimensions on body measurements of milking cows (Süss, 1994; Anderson, 2003; Keil et al., 2004). Two assumptions are implicit in this second approach. The first is that body measurements are highly correlated (e.g. body length and withers height), even in animals of different size. These correlations are only high in young cattle, however (Jauschnegg, 1994). The second is that body measurements can be used to describe the space needed in cubicles by means of simple univariate regression, which can serve as a rule of thumb (e.g. diagonal body length for the length of cubicles and height at withers for the width of cubicles; Commission Internationale du Génie Rural (CIGR, 2002) and Anderson (2003)). Thirdly, 3-D kinematics have recently been used to directly estimate space requirements of cows while lying down (Ceballos et al., 2004). Whereas measurements obtained with the latter method directly show the space needed by cattle, the 'trial-and-error' solutions and the rules of thumb have in almost no cases been verified on the basis of behavioural observations assessing the space actually needed by cows when lying, lying down or standing up (an exception is Keil et al. (2004)). It is therefore hardly surprising that recommendations for cubicle size for adult dairy cows span quite a broad range from about 110 to $135 \mathrm{~cm}$ in width and 220 to $270 \mathrm{~cm}$ in length (Figure 1).

Unlike with dairy cows, there are no studies and hardly any recommendations on the appropriate dimensions of cubicles for growing cattle (Kuratorium für Technik und Bauwesen in der Landwirtschaft (KTBL, 1991), Müller (1994), Süss (1994), Holmes (2000), CIGR (2002); see Figure 1), and none specific to finishing bulls. Beef cattle may have different proportions

(a)

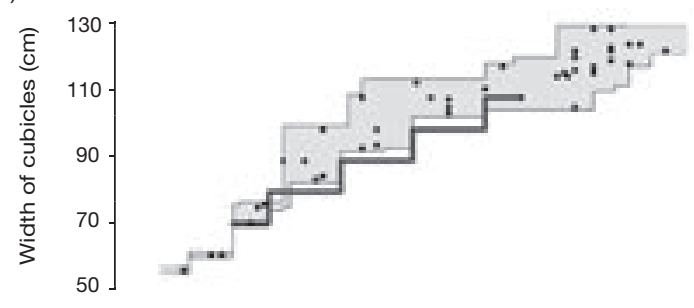

(b)

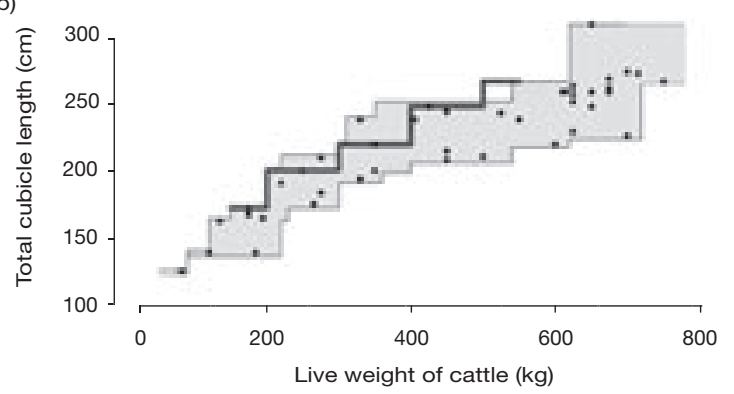

Figure 1 Range of recommendations of (a) cubicle width and (b) total cubicle length (length of lying area plus length of head space for cubicles facing a wall and allowing a forward lunge) for dairy cows and replacement cattle, as indicated by the grey area. Each point indicates the mean of one recommendation. Dimensions used in the current experiment are added with the dark-grey solid lines (data from KTBL (1991), Müller (1994), Süss (1994), McFadden et al. (1995), Bartussek et al. (1996), Grandle et al. (1996), Bickert (1999 and 2000), Holmes (2000), Hilty (2001), CIGR (2002), Anderson (2003) and Hanselmann (2004)). of body dimensions from dairy cows. Moreover, young bulls are growing fast, so cubicle size must be adjusted to their body size several times over the fattening period.

In our study, we wanted to investigate how well the cubicle dimensions recommended for replacement cattle can be applied to finishing bulls. Therefore, we increased the size of the cubicles at four points in time during the finishing periods of bulls (from on average 160 to $550 \mathrm{~kg}$ ), and observed the animals' behaviour shortly before and after enlargement of the cubicles. In practice, groups are usually shifted between pens with increasing cubicle dimensions. We tested whether the bulls' behaviour changed with the enlargement, in order to determine whether the size of the cubicles and the points in time at which they were enlarged were aptly chosen. In addition, we rated the cleanliness of the animals and of the lying surface before and after enlargement to identify problems with hygiene, caused, for example, by the bulls turning around in the cubicles before lying down and then later defecating on the front part of the lying surface.

In accordance with observations that the quality of standingup and lying-down movements change according to the quality of the lying-area (dairy cows: Sambraus (1971), Lidfors (1989), Mogensen et al. (1997); beef cattle: Konrad (1988)) and assuming that space was restricted before enlargement, we hypothesized that the bulls would have fewer lying bouts in the smaller cubicles, in order to avoid standing up and lying down, and that they would interrupt standing-up and lying-down movements more often, show intensified preparations for standing up and lying down, and bump into the cubicle boundaries (partitions, neck rail) more frequently. On the other hand, we expected dirtier animals and lying surfaces in the larger cubicles.

\section{Material and methods}

\section{Animals and housing}

The experiment was conducted at the facility of the Swiss Federal Research Station for Agricultural Economics and Engineering (Agroscope FAT Tänikon). Twenty finishing bulls of various breeds (six Brown Swiss, two Limousin, one each of the Red Holstein, Blond d'Aquitaine and Swiss Simmental breeds, and nine crossbreeds) were kept in four groups of five bulls each. Initially, they were assigned to groups so as to yield a similar weight and breed distribution for each group. Each pen (housing one group) had a solid-concrete walking area of about $30 \mathrm{~m}^{2}$ and five cubicles, separated by cantilevered loop partitions (made of metal pipes with a round cross section) and limited at the front end by a wooden wall, equipped with soft lying mats at an inclination of $5 \%$ (Schulze Westerath et al., 2004). Across the back of the cubicles a pipe was installed to avoid mounting. Bulls stepped into the cubicles under this pipe. Head space was sufficiently large that it should provide enough space to allow a forward lunge (Table 1). All cubicles in a given pen were equipped with one of two mat types (Kraiburg KSL rubber mat with nubs on the bottom; Boutech foam EVA green mat), and the lying area was either sparsely littered with chopped straw, or bare (each mat type/litter combination was provided in one pen and remained unchanged over the entire growth period). The lying area of all cubicles was cleaned after the morning 


\section{Cubicle dimensions and behaviour of finishing bulls}

Table 1 Cubicle dimensions used for each live-weight range and actual live weight of the animals (the class above $500 \mathrm{~kg}$ in italics was used in this study for comparative purposes only and is not usually included in recommendations for animals up to $550 \mathrm{~kg}$ )

\begin{tabular}{|c|c|c|c|c|c|}
\hline \multirow[b]{3}{*}{ Actual weight $(\mathrm{kg}) \pm$ s.e. ${ }^{\dagger}$} & \multicolumn{5}{|c|}{ Weight class (kg) } \\
\hline & $<201$ & $201-300$ & $301-400$ & $401-500$ & $>500$ \\
\hline & $221.1 \pm 6.9$ & $328.8 \pm 8.4$ & $382.7 \pm 9.7$ & $492.3 \pm 9.2$ & \\
\hline Length of lying area (cm) & 120 & 140 & 150 & 185 & 185 \\
\hline Length of cubicle (cm) & 160 & 190 & 210 & 240 & 260 \\
\hline Width (cm) & 70 & 80 & 90 & 100 & 110 \\
\hline \multicolumn{6}{|l|}{ Neck rail } \\
\hline Height above lying area & 85 & 90 & 95 & 100 & 105 \\
\hline
\end{tabular}

† Weights reached in the experiment at the end of the respective weight class.

feeding and topped up with litter as necessary in the two pens containing straw. Additional straw was also provided in the afternoon.

Bulls were given food once daily in the morning with an ad libitum ration of (per $\mathrm{kg}$ ) $900 \mathrm{~g}$ maize silage and $100 \mathrm{~g}$ hay, with $2 \mathrm{~kg}$ concentrate added per animal. In the afternoon, any remaining ration was pushed towards the feeding rack.

\section{Observational design}

Since several animals had turned around in the cubicles in a previous experiment, we chose cubicle dimensions that were rather narrow and long compared to the available recommendations (Figure 1). Bulls were put into the experimental pens at an average weight of $160 \mathrm{~kg}$. Cubicles are often enlarged at fixed intervals. In our study, we attempted to do so when bulls reached average weights of $200,300,400$ and $500 \mathrm{~kg}$ (Table 1, Figure 1). At each of these four points in time, data on bull behaviour were recorded up to 3 to 7 days before enlargement in 'small' cubicles, and after 7 to 12 days after enlargement to 'large' cubibles. Bulls were thus allowed at least 1 week to get used to the enlarged cubicles before data collection commenced. Observations were made in eight experimental situations: before and after enlargement at four points in time (time/enlargement combinations). Animals were weighed, and cleanliness of animals and cubicles was assessed about every 4 weeks based on a dirtiness scoring system. Data of the dirtiness scoring which was closest to the point of enlargement of the cubicles was assigned to the respective 'small' and 'large' cubicles (usually about 2 weeks before and after the enlargement). Observations took place from April to December 2003. To account for general changes over the seasons, we included time as an explanatory variable in the evaluation (see Statistical analysis section).

\section{Parameters}

The quality of standing-up and lying-down movements was quantified by direct observations. The observers were about $6 \mathrm{~m}$ away from the cubicles and had an unobstructed view of the animals. We assessed (1) whether standing-up was atypical (forelegs first), interrupted (bulls got up onto their hind legs and carpal joints, and then lay down again), or done only to change lying sides (i.e. bulls getting up onto their carpal joints and lying down on the other side), and how many head lunges were needed to get up; (2) whether lying down was atypical (hindlegs first) or interrupted (bulls lowered themselves onto the carpal joints and then stood up again), how many times bulls stepped with their forelegs and hindlegs, and whether intensive head sweeps (more than three to-and-fro movements) occurred before lying down; (3) whether bulls slipped or fell while standing up or lying down; (4) whether they hit the cubicle partitions; and (5) whether they turned around in the cubicle.

We attempted to collect data on 10 instances each of standing up and lying down per bull and experimental situation. A total of 1937 standing-up and 1993 lying-down instances were observed (minimum, lower quartile, median, upper quartile and maximum per bull per time/enlargement combination were for standing-up: $0,10,11,14,27$; and for lying-down: 1, 10, 12, 15 and 34 instances, respectively). These direct observations were carried out for about $5 \mathrm{~h} /$ day split in half (i.e. $2.5 \mathrm{~h}$ in the mornings, from 09:30 to 12:00 h, and $2.5 \mathrm{~h}$ in the afternoons from $13: 30$ to $16: 00 \mathrm{~h}$, on 4 to 7 days for each of the eight experimental situations).

Average lying duration in $24 \mathrm{~h}$ and average number of lying bouts per group were measured automatically using distance sensors positioned above the cubicles. These sensors were able to differentiate between an empty cubicle, a cubicle with a standing or a cubicle with a lying bull (for technical details see Schulze Westerath et al. (2002)). Data from the distance sensors were collected every minute on three consecutive days for each time/enlargement combination.

Around the fourth enlargement of the cubicles, we expanded on our observations by including lying postures. Cubicles were photographed every $10 \mathrm{~min}$ on behavioural observation days. On average, 65 (range: 41 to 82 ) photographs showed the animal lying before enlargement, and 93 (range: 65 to 118) after enlargement. Based on these photographs, the proportion of scans in which the animals lay with outstretched legs (at least one foreleg partly stretched, i.e. not held close to rump, or at least one hindleg stretched with an angle of more than 90 degrees at the tarsal joint), on their side and in physical contact with their neighbours was calculated.

The dirtiness and wetness of the animals and of the lying area in the cubicles were rated early in the morning on 3 days consecutively using a slightly extended scheme taking different regions of the body into account and described by Faye and Barnouin (1985). For each of the body regions dirtiness and wetness was estimated as a score ranging from 0 to 2 in increments of 0.5 from clean to completely soiled, and dry to wet, respectively. For the analysis, an average 


\section{Gygax, Schulze Westerath, Kuhlicke, Wechsler and Mayer}

score was calculated per bull and experimental situation (time/enlargement combination) for dirtiness of the rear part of the bulls (hind legs and area around tail), the lower part of the body (belly and sternum), and the front part of the body (shoulders and forelegs), as well as for overall dirtiness (all body parts taken together).

Dirtiness and wetness of the cubicles were rated twice daily on the same days. The front two-thirds and rear third of the lying area were scored separately. The score indicated how many quarters of the area were dirty/wet (e.g. score $=2: 25$ to $50 \%$ of the area). Additionally, the number of dung heaps were counted in the two areas. For evaluation, these scores were averaged per group and experimental situation.

\section{Statistical analysis}

Linear and generalized linear mixed-effects models (using a binomial distribution) were used to evaluate the different behavioural and cleanliness parameters (Pinheiro and Bates, 2000; Venables and Ripley, 2002; calculated using R 1.8.1, www.r-project.org). These models are estimated using a restricted maximum-likelihood method and are therefore robust regarding unbalanced data sets (Pinheiro and Bates, 2000). The models were of the form

$$
y_{i j k l m n o}=\mu+b_{i}+b_{i j}+b_{i j k}+\alpha_{1}+\beta_{m}+\gamma_{n}+\delta_{o}+\gamma \delta_{n o}+\varepsilon_{i j k l m n o}
$$

with the fixed effects of $\alpha_{l}=$ litter (no - yes, d.f. $=1$ ), $\beta_{\mathrm{m}}=$ type of lying mat $(0,1$, d.f. $=1), \gamma_{\mathrm{n}}=$ points in time (ordered factor, d.f. $=3$ ), $\delta_{\circ}=$ enlargement (small, large, d.f. $=1)$ and $\gamma \delta_{n o}=$ the interaction of points in time and enlargement (d.f. $=3$ ) and with the nested random effects $b_{i}=$ group, $b_{i j}=$ individual and $b_{i j k}=$ the time/enlargement combination. Statistical assumptions are that $\varepsilon_{\mathrm{ijk} \mid m n o} \sim N(0$, $\left.\sigma^{2}\right)$ iid, $b_{i} \sim N\left(0, \sigma_{1}{ }^{2}\right)$ iid, $b_{i j} \sim N\left(0, \sigma_{2}{ }^{2}\right)$ iid and $b_{i j k} \sim N(0$, $\sigma_{3}{ }^{2}$ ) iid (iid = independently identically distributed). These assumptions, homoscedasticity and independence of the residuals from the explanatory variables were checked using graphical analysis of residuals. For response variables that described the occurrence of events, the binomial distribution was used (standing-up with more than one head lunge, hitting partitions, interrupted lying-down, high-intensity of head sweeps, slipping). For continuous response variables, the response was log- (animal dirtiness score, number of dung heaps) or square-root-transformed (stepping before lying down) if necessary to ensure assumptions on the distribution of the residuals. The other response variables remained untransformed (lying duration, number of lying bouts, cubicle dirtiness).

The time/enlargement combination was introduced such that each instance of standing up and lying down could be used separately in the model without inflating the degrees of freedom, i.e. the overall sample for these tests was taken to be the number of bulls times the number of experimental situations. This is analogous to evaluating proportions of occurrences or means per individual for each time/ enlargement combination.

In the Results section, the statistical results of the parameter enlargement will be presented and discussed. Where necessary, the influence of the points in time on enlargement will also be considered (statistical interaction between time and enlargement). However, as it is not possible to determine whether the influence of the points in time is an effect of the season, growth or ontogenetic development of the bulls, the variable time was included for the sake of completeness only, and no attempt at interpretation is made.

The two mat types and presence or absence of straw on the lying area were included in the experimental design though their statistical power (four groups) was weak. They were included in the analysis of the current study to completely reflect the experimental situations. Since they were never close to statistical significance, however, they are not presented in the Results section.

Lying postures at time-point 4 were compared for 'small' and 'large' cubicles using a Wilcoxon matched-pairs test with test statistic $V$ based on the individual bulls' data.

\section{Results}

\section{Quality of standing-up and lying-down movements}

Interrupted standing up was never observed, and atypical standing up was observed only once. In $2 \%$ of all standingup events, bulls merely changed the side on which they were lying, and these rare instances did not depend on cubicle size. The proportion of standing-up instances with more than one head lunge decreased with the enlargement of the cubicles $\left(F_{1,130}=6 \cdot 82, P=0 \cdot 01\right.$, Figure 2a). On average, bulls bumped into partitions $23 \%$ of all the times they stood up. Partitions were hit less often after enlargement of the cubicles. In particular, and in decreasing proportion of occurrence, bulls less often bumped their necks on the neck rail $\left(F_{1,130}=6 \cdot 3, P=0.013\right)$, their heads on the partition $\left(F_{1}\right.$, $\left.{ }_{130}=8 \cdot 6, P=0.004\right)$, their heads on the front end of the cubicle (except at time-point 1, interaction : $F_{3,130}=6 \cdot 8, P<0.001$ ) and their rumps on the partition $\left(F_{1,130}=5 \cdot 7, P=0.02\right)$. Consequently, the proportion of standing-up movements in which any bump occurred also decreased with enlargement of the cubicles $\left(F_{1,130}=10 \cdot 7, P=0 \cdot 001\right.$, Figure $\left.2 b\right)$.

Atypical lying down was never observed. Interrupted lyingdown attempts were quite rare (for most animals in most experimental situations, a zero proportion of all lying-down instances, which only rarely rose to 0.5$)$, and did not change in proportion with enlargement of the cubicles $\left(F_{1,131}=0 \cdot 19\right.$, $P=0.67)$. The proportion of lying-down instances with a high intensity of head sweeps did not consistently change with enlargement of the cubicles $\left(F_{1,131}=0.44, P=0.51\right.$, Figure $2 \mathrm{c})$. Bulls hit the cubicle partitions mostly with their rumps while lying down (about 17\% of all lying-down instances). More rarely, they hit the partition with their head or legs, the neck rail with their necks, or the front end of the cubicle with their heads. None of these individual instances of bumping showed a systematic change with enlargement, but the total number of bumps decreased with enlargement (except at time-point 1 , interaction : $F_{3,131}=4 \cdot 2, P=0.007$, Figure $2 d$ ). After enlargement of the cubicles, bulls more often stepped with their forelegs before lying down (except at time-point 3 , interaction: $F_{3,131}=4 \cdot 19, P=0 \cdot 007$, Figure $\left.2 e\right)$, but the number of steps with their hindlegs did not change $\left(F_{1}\right.$, ${ }_{131}=0 \cdot 60, P=0 \cdot 44$, Figure 2f). 


\section{Cubicle dimensions and behaviour of finishing bulls}

Bulls never turned around in the cubicles. Moreover, they never fell, and seldom slipped, while standing up or lying down. On average, they slipped on their front claws in only $1 \%$ and their hind claws in only $0.6 \%$ of all instances of standing up and lying down. Nevertheless, the total proportion of slipping increased with enlargement of the cubicles $\left(F_{1,131}=4 \cdot 19, P=0.043\right.$, Figure 3a; foreclaws : $F_{1}$, ${ }_{131}=7 \cdot 45, P=0 \cdot 055$; hindclaws : $\mathrm{F}_{1,131}=0 \cdot 24, P=0 \cdot 63$ ).

\section{Lying behaviour}

Mean daily lying duration per group and time/enlargement combination varied between 625 and 893 min (Figure 3b), and on average was split into 11.3 to 20 bouts per day (Figure 3c). On average, the duration of lying decreased $\left(F_{1,21}=9 \cdot 3, P=0.006\right.$, Figure $\left.3 b\right)$ while the number of lying bouts tended to increase with enlargement of the cubicles $\left(\mathrm{F}_{1,21}=4 \cdot 2, P=0.052\right.$, Figure $\left.3 \mathrm{c}\right)$.

At time-point 4, we observed that the proportion of scans in which bulls lay with outstretched forelegs or hindlegs did not change with enlargement (Wilcoxon test based on the individual bulls; $\mathrm{V}=91, P=0.89$ ), nor did the proportion of scans in which bulls lay on their side (Wilcoxon test : $V=71$, $P=0 \cdot 81)$. Where at least one adjacent cubicle was occupied,
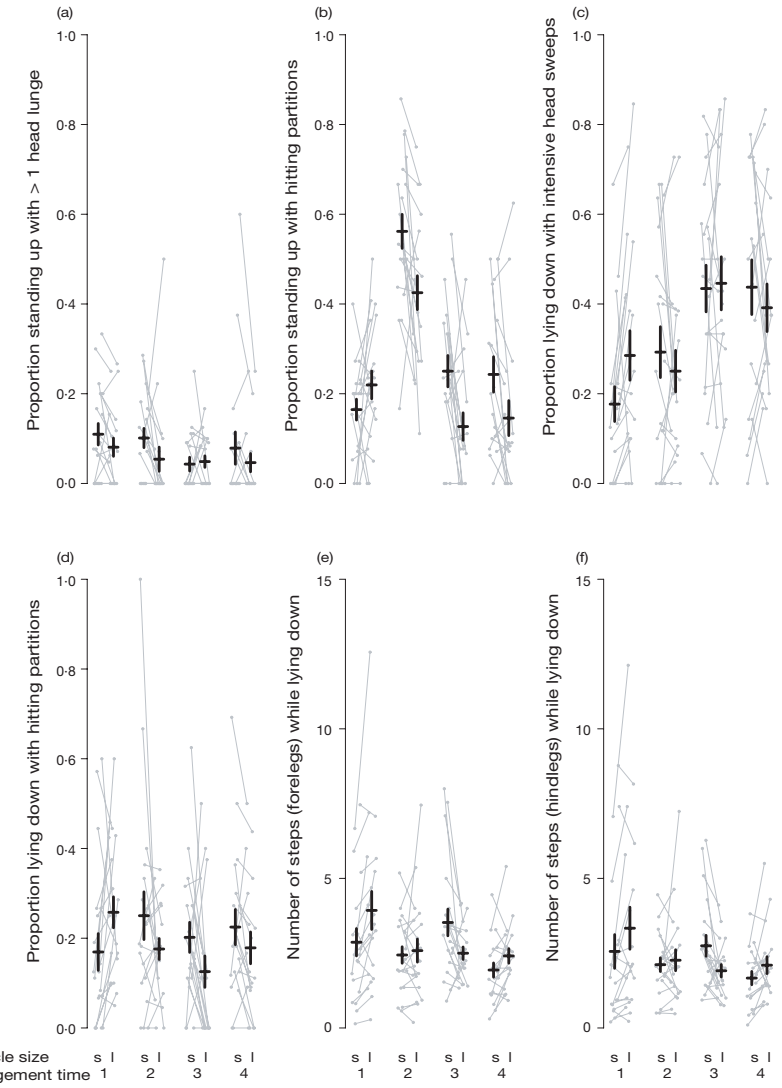

Figure 2 Behaviour of bulls at the four points in time, each before and after enlargement of the cubicles ( $\mathrm{s}=$ 'small', I = 'large' cubicles): proportion of standing-up movements involving (a) more than one head lunge and (b) hitting partitions; proportion of lyingdown movements involving (c) intensive head sweeps and (d) hitting partitions; number of steps taken with (e) forelegs and (f) hindlegs before lying down. Data of the individual bulls are given as grey lines. Mean \pm s.e. are given as black crosses for each observational period. bulls tended to be in physical contact with their neighbours in a lower proportion of scans when the cubicles were enlarged (Wilcoxon test : $V=140, P=0.07$ ).

\section{Animal and cubicle cleanliness}

Bulls were hardly ever dirty on belly or front part of their body. Individual bulls had maximum average dirtiness scores of 0.6 on a scale of 0 to 2 (median : 0 ) in these areas per time/enlargement combination. Dirtiness of the rear part of the bulls did not change with enlargement $\left(F_{1,130}=0.39\right.$, $P=0.53$ ), while overall dirtiness increased with enlargement at time-point 3 (interaction : $F_{3,130}=5 \cdot 5, P<0 \cdot 001$, Figure $3 d$ ). Bulls were hardly ever wet (median of 0 , maximum 0.3 on a scale of 2, Figure 3e).

The front two-thirds of the lying area was rarely dirty (median 0.17 , maximum 0.8 on a scale of 4 ), wet (median 0.03 , maximum 0.26 on a scale of 4 ) or fouled with dung heaps (median 0, maximum 0.03) at all. The dirtiness of the rear third of the lying area tended to increase with enlargement of the cubicles $\left(F_{1,21}=3.44, P=0.08\right.$, Figure $\left.3 f\right)$. The wetness of the rear third of the lying area increased after cubicle enlargement (except at time-point 3, interaction : $F_{3,21}=4 \cdot 6$, $P=0.01$, maximum value at 1 on a scale of 4$)$. The number
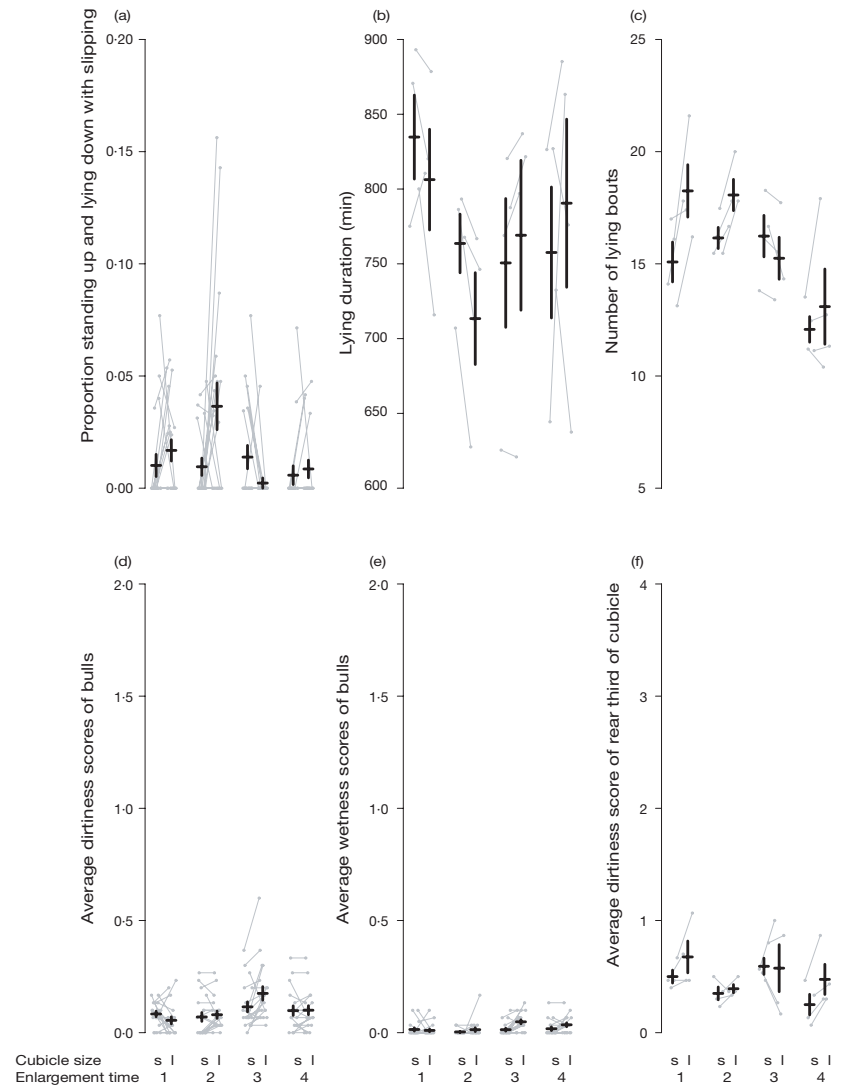

Figure 3 Behaviour and cleanliness at the four points in time, each before and after enlargement of the cubicles ( $s=$ 'small', I = 'large' cubicles): (a) proportion of standing-up and lying-down movements with slipping, (b) lying duration, (c) number of lying bouts, (d) average dirtiness scores and (e) average wetness scores of the bulls, and (f) average dirtiness scores of the rear third of the cubicles. Data of the individual bulls (a), (d) and (e), average data per group (b), (c) and (d) and average data per pen (f) are given as grey lines. Mean \pm s.e. are given as black crosses for each observational period. 


\section{Gygax, Schulze Westerath, Kuhlicke, Wechsler and Mayer}

of dung heaps on the rear third of the lying area increased with enlargement (except at time-point 4 , interaction : $F_{3}$, ${ }_{21}=6 \cdot 4, P=0.003$, maximum number of dung heaps was 0.5 per cubicle).

\section{Discussion}

Most of the parameters investigated in this study do not clearly favour either large or small cubicles at the timepoints chosen for enlargement. There were no differences between small and large cubicles in terms of the following variables : interrupted attempts to stand up or lie down; atypical ways of standing up or lying down; the proportion of changes onto a different lying side; the proportion of intensive head sweeps; the number of instances of stepping with the hindlegs when preparing to lie down; the occurrence of falls; how often bulls lay on their side; changes in most of the cleanliness measurements of the bulls and the lying area (Table 2). In contrast to the results of Hörning and Tost (2002) in dairy cows, we did not observe changes in terms of how often hindlegs were stretched out in larger cubicles.

On the other hand, the bumping into cubicle boundaries (partitions, neck rail and front boundary) decreased with enlargement of the cubicles, thus indicating the necessity of enlarging cubicles at the time-points examined in this study (Table 2). These bumps were not usually severe, however. In most cases, animals touched rails and partitions in the final phases of standing up or lying down, so that these bumps do not seem to indicate a serious restriction

Table 2 Summary of the parameters investigated, with a rating of the effects due to enlargement of the cubicles

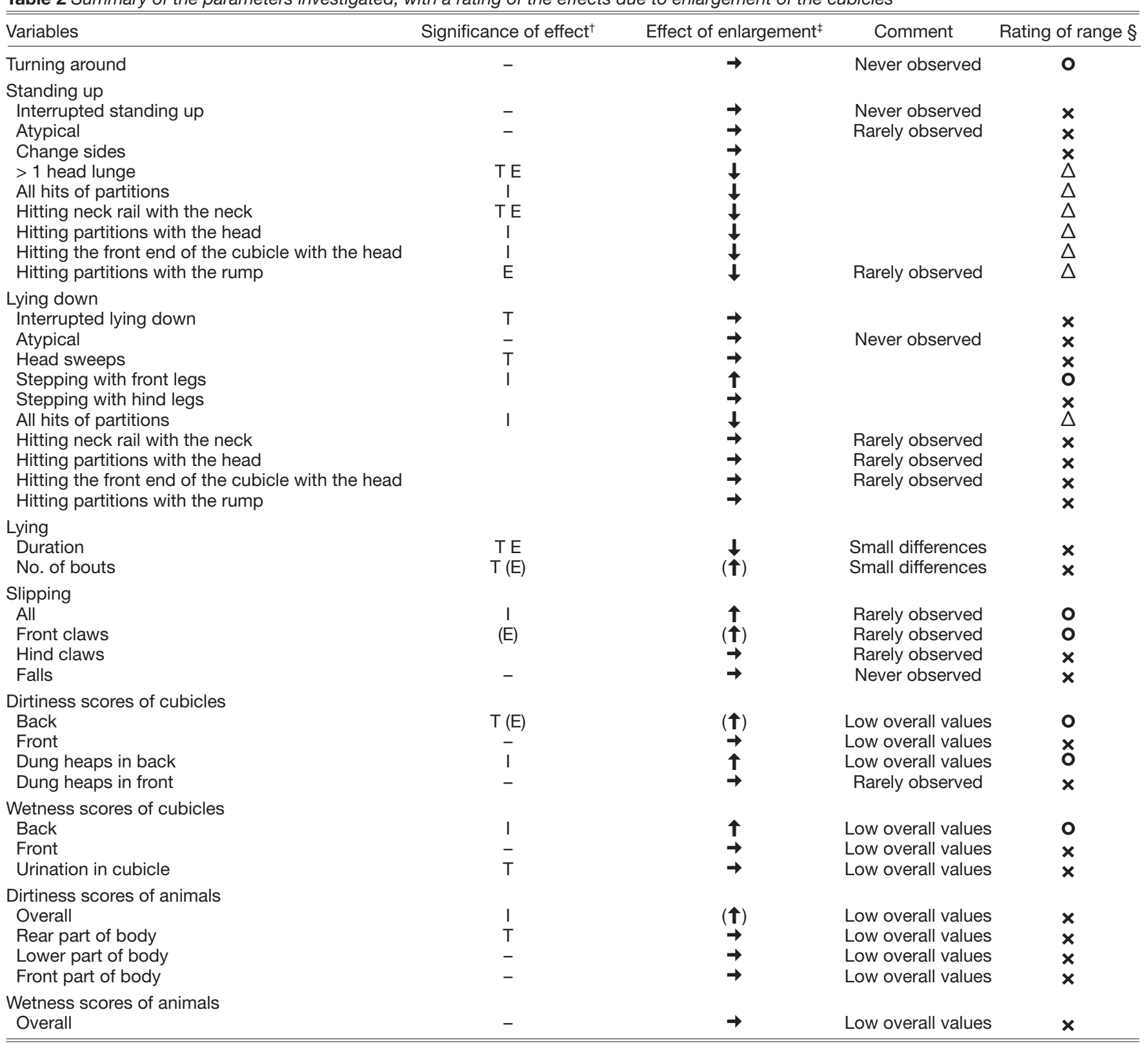

${ }^{+} P<0.05$, in parentheses if $P<0.10$ : significant results for points in time, T; enlargement, E; interaction, I; no test conducted, - .

‡Effect of enlargement: $\rightarrow=$ no change, $\uparrow=$ increase, $\downarrow=$ decrease from 'small' to 'large' cubicles. In parentheses if only a tendential or very small difference on an absolute scale.

$\S$ Rating of change: $\mathbf{O}=$ smaller cubicles better, $\Delta=$ smaller cubicles worse, $\mathbf{x}=$ no difference. 


\section{Cubicle dimensions and behaviour of finishing bulls}

in the bulls' behaviour. Also militating in favour of cubicle enlargement is the fact that bulls more often performed more than one head lunge while standing up in the smaller cubicles, indicating that standing up was easier in the larger cubicles. Similarly, Tucker et al. (2004) found that cows stood longer in narrow cubicles, which potentially indicates that the animals found it more difficult to lie down in a narrower space.

In contrast to the observations of Tucker et al. (2004) in dairy cows, total lying duration (10 to $15 \mathrm{~h}$ per day) decreased with enlargement of the cubicles. In addition, the number of lying bouts (10 to 20 per day) increased with enlargement. At each point in time, however, these differences between small and large cubicles were fairly minor on an absolute scale, and none of the values was outside the range reported in some previous studies (Andreae, 1979; Graf, 1984; Hartmann and Schlichting, 1990; Minonzio et al., 1992) and both, total lying duration and number of lying bouts, were higher than the data reported and summarized in Bockisch (1991). Huge changes in lying duration were not to be expected, as these measurements are assumed to depend mainly on the softness of the lying surface (Andreae and Papendieck, 1971; Andreae, 1979; Graf, 1984; Konrad, 1988; Frickh et al., 2000).

There were even several factors indicating that, at a given point in time, the smaller cubicles provided advantages for the bulls : bulls stepped less often with their forelegs before lying down, slipped less often, and the back third of the cubicles were cleaner and drier before enlargement of the cubicles (Table 2). In principle, the increase in the number of steps taken might also be due to the relatively short time the bulls had to get used to their new surroundings after the cubicles were enlarged, but this would be the only indication of too little familiarization time. Nevertheless, this result contrasts with the negative correlation between the number of steps taken before lying down and the size of the cubicles found by Hörning and Tost (2002) in the case of dairy cows. The increased dirtiness and wetness of the rear third of the cubicles parallels the findings of Tucker et al. (2004), who weighed increasingly large quantities of faecal matter with increasing width of the cubicles for dairy cows. In our study, this did not directly translate into reduced animal cleanliness, but it is likely that the cubicles were better cared for in our research facility than one might expect them to be in practice. Finally, bulls never turned around in the cubicles, in contrast to an earlier study with cubicles $10 \mathrm{~cm}$ wider, in which at least one animal in each of four groups turned around in the cubicles before lying down. We still do not know for certain why bulls like to turn around, whether just to avoid stepping backwards or because they like to keep other bulls in view. It is thus currently unclear whether restriction of the motivation to do so could have negative consequences for the welfare of finishing bulls.

Summarizing our results, it would appear that bulls were not strongly restricted in their behaviour in the small cubicles as compared with the larger cubicles at each point in time when cubicles were enlarged. Thus, our long, narrow cubicles (Figure 1) would seem to be an adequate compromise for finishing bulls, a conclusion similar to the one reached by
Tucker et al. (2004) for dairy cows based on the length of time they spent standing in the cubicle with only the front hooves on the lying surface. The lack of significant changes in behaviour and cleanliness in our study after enlargement of the cubicles corresponds to results of a survey conducted by Veissier et al. (2004), who found no influence of cubicle size on the behaviour, injuries and cleanliness of dairy cows. In a direct-choice test with dairy cows, Tucker et al. (2004) found only a very slight preference for wide $(132 \mathrm{v} .112 \mathrm{~cm})$ and long $(274$ v. $229 \mathrm{~cm})$ cubicles, indicating that the cows do not react strongly to small changes in cubicle size.

Rules of thumb to derive cubicle measurements from the size of cattle are usually based on simple, bivariate correlations of different body measurements (e.g. Jauschnegg, 1994). If those relationships are not fully described by a linear pattern, however, such rules of thumb have to be considered as oversimplified. Observing how cattle deal with given cubicle dimensions, as we have done in the current study, or directly measuring space requirements for e.g. standing up and lying down when animals can move freely (Ceballos et al., 2004), are more straightforward approaches for identifying adequate cubicle dimensions for cattle.

\section{Conclusion}

Enlargement of the cubicles as investigated in this study had fewer favourable effects on the behaviour of the bulls than anticipated. At each point in time, the smaller cubicles still seemed to provide sufficient lying space for the bulls. However, the benefits of cubicle enlargement were a reduced frequency of impacts with the partitions and lower numbers of head lunges while getting-up. If it is assumed that the contacts with the partitions were not a welfare issue (in terms of discomfort, pain or injury to the bulls), as suggested by our qualitative observations, the enlargement of the cubicles to the dimensions used in this study for the various live-weight classes were appropriate for the types of finishing bulls studied.

\section{Acknowledgements}

We would like to thank G. Jöhl, R. Rutishauser and P. Brändle for setting up the cubicles and helping with weighing the animals, F. Salzgeber and U. Marolf for looking after the bulls, and E. Hillmann, $\mathrm{N}$. Keil and two anonymous referees for helpful comments on the manuscript. This research was supported by grants from the Swiss Federal Veterinary Office (2.01.05 and 2.03.05).

\section{References}

Anderson, N. 2003. Free stall dimensions. Ontario Ministry of Agriculture and Food. http: //www.gov.on.ca/OMAFRA/english/ livestock/dairy/facts/info_fsdimen. htm

Andreae, U. 1979. [Activity of finishing bulls kept on fully slatted floors.] Landbauforschung Völkenrode 48: (Special issue) 89-94.

Andreae, U. and Papendieck, T. 1971. [Behaviour of dairy cows when choosing a cubicle in loose housing systems.] Der Tierzüchter 15: 432-435.

Bartussek, H., Leeb, C. and Held, S. 1996. Animal needs index for cattle, TGI 35L/2000 - cattle. BAL Gumpenstein, Irdning. http: //www.gumpenstein.at/publikationen/ignreport/ani35lc.pdf

Bickert, W. G. 1999. Building and remodeling freestall housing for cow comfort. Proceedings of the Western Canadian Dairy seminar, http: //www.wcds.afns.ualberta.ca/Proceedings/1999/chap29.htm 


\section{Gygax, Schulze Westerath, Kuhlicke, Wechsler and Mayer}

Bickert, W. G. 2000. Milking herd facilities. In Dairy freestall, housing and equipment, MWPS-7 (ed. W. G. Bickert, B. Holmes, K. Janni, D. Kammel, R. Stowell and J. Zulovich), pp. 27-46. MidWest Plan Service MWPS, lowa State University, Ames, IA.

Bockisch, F.-J. 1991. [Quantification of interactions between dairy cows and their housing environment; fundamentals for the improvement of housing systems and their economic judgement.] Habilitation. Verlag der Feber'schen Universitäts-Buchhandlung, Giessen

Ceballos, A., Sanderson, D., Rushen, J. and Weary, D. M. 2004. Improving stall design: use of 3-D kinematics to measure space use by dairy cows when lying down. Journal of Dairy Science 87: 2042-2050.

Commission Internationale du Génie Rural. 2002. Design recommendations of beef cattle housing. Bundesanstalt für alpenländische Landwirtschaft, Gumpenstein

Faye, B. and Barnouin, J. 1985. [An objective score of the cleanliness of dairy cows and housing systems. ] Bulletin Technique, Centre de Recherches Zootechniques et Vétérinaires de Theix, INRA 59: 61-67.

Frickh, J., Karall, P., Stanek, C., Troxler, J., Keller, M., Hinterhofer, C. and Spergser, J. 2000. [The effect of housing and feeding on behaviour, claw health and production of Holstein bulls.] Der Förderungsdienst 48: 369-374.

Graf, B. 1984. [The effect of different loose housing systems on the behaviour of finishing oxen.] Dissertation, ETH Zürich.

Grandle, G., Bowling, R., Buschermohle, M., Crist, W., Hunter, D., Sliger, R., Trimble, R., and Turner, L. 1996. Milking herd feeding and housing facilities. In UT Extension. Sustainable dairy systems planning manual, pp. 1-28. The University of Tennessee, Knoxville, Tennessee, USA.

Hanselmann, D. 2004. [Larger and larger?] Zuchtwahl und Besamung 151: 1-3.

Hartmann, H. and Schlichting, M. C. 1990. [Behaviour of finishing bulls in loose housing systems with electronic feeding.] KTBLSchrift 342: 197-207.

Hilty, R. 2001. [Dimensions of housing systems.] Agroscope FAT Tänikon. http://www.fat.admin.ch/e/ (publications, recommendations)

Holmes, B. 2000. Replacement housing. In Dairy freestall, housing and equipment, MWPS-7 (ed. W. G. Bickert, B. Holmes, K. Janni, D. Kammel, R. Stowell and J. Zulovich), pp. 1-26. MidWest Plan Service MWPS, lowa State University, Ames, IA.

Hörning, B. and Tost, J. 2002. [Multivariate analysis of factors influencing the resting behaviour of dairy cows in cubicle housing systems.] KTBL-Schrift 407: 139-151.

Jauschnegg, H. 1994. [Weight and body size of cattle.] Diploma thesis, Österreichisches Kuratorium für Landtechnik, Vienna.

Keil, N., Gisiger, E. and Stauffacher, M. 2004. [Evaluation of the dimensions of cubicles for cattle based on the lying behaviour of dairy cows of varying body size]. KTBL-Schrift 431: 115-121.

Konrad, S. 1988. [Evaluation of housing systems for finishing bulls based on indicators.] KTBL-Schrift 323: 214-230.

Kuratorium für Technik und Bauwesen in der Landwirtschaft 1991. [Cubicles for dairy cows and growing cattle.] KTBL-Arbeitsblatt 1002, http://www.ktbl.de/KTBLPUBFORM/DDW?W=(BESTELLNU MMER='21002')

Lidfors, L. 1989. The use of getting up and lying down movements in the evaluation of cattle environments. Veterinary Research Communications 13: 307-324.
Lowe, D. E., Steen, R. W. J., Beattie, V. E. and Moss, B. W. 2001. The effect of floor type systems on the performance, cleanliness, carcass composition and meat quality of housed finishing beef cattle. Livestock Production Science 69: 33-42.

McFadden, V. J., Lorimor, J., Kohl, K. and Wells, G. 1995. Freestall housing for livestock. lowa State University. http: //www.extension. iastate.edu/Publications/PM1610. pdf

Mayer, C., Schrader, L., Fietz, D. and Schulze Westerath, H. 2002. [Animal protection issues in finishing cattle - a comparison of different housing systems.] In Tagung der Fachgruppen Tierschutzrecht und Tierzucht, Erbpathologie und Haustiergenetik in Verbindung mit der Fachhochschule Nürtingen (ed. Deutsche Veterinärmedizinische Gesellschaft), pp. 129-135.

Meier, T., Schulze Westerath, H., Mayer, C. and Gygax, L. 2004. [Optimal inclination of the lying area in cubicles for fattening bulls.] KTBL-Schrift 431: 122-128.

Minonzio, G., Gloor, P. and Huber-Hanke, R. 1992. [Straw-floor systems for cattle.] FAT-Schriftenreihe 35: 1-104.

Mogensen, L., Krohn, C. C., Sørensen, J. T., Hindhede, J. and Nielsen, L. H. 1997. Association between resting behaviour and live weight gain in dairy heifers housed in pens with different space allowance and floor type. Applied Animal Behaviour Science 55: 11-19.

Müller, P. 1994. [Housing systems for growing cattle.] KTBLArbeitsblatt 1095. http: //www.ktbl.de/ab/ab1095/ab1095.htm

Pinheiro, J. C. and Bates, D. M. 2000. Mixed-effects models in S and S-PLUS. Springer, New York.

Ruis-Heutinck, L. F. M., Smits, M. C. J., Smits, A. C. and Heeres, J. J. 2000. Effects of floor type and floor area on behaviour and carpal joint lesions in beef bulls. In Improving health and welfare in animal production (ed. H. J. Blokhuis, E. D. Ekkel and B. Wechsler), EAAP publication no. 102, pp. 29-36.

Sambraus, H. H. 1971. [Lying behaviour of ruminants.] Züchtungskunde 43: 187-198.

Schulze Westerath, H., Gygax, L. and Mayer, C. 2005. [Lying behaviour of fattening bulls kept in cubicles with soft lying mats.] KTBL-Schrift 437: 42-50.

Schulze Westerath, H., Mayer, C. and Bollhalder, H. 2002. Automated registration of cubicle occupation in a cubicle housing system. Bornimer Agrartechnische Berichte 29: 169-172.

Schulze Westerath, H., Meier, T., Gygax, L. and Mayer, C. 2004. Optimising the inclination of the lying area in cubicles for fattening bulls. Proceedings of the 38th international congress of the ISAE 2004, p. 128.

Schulze Westerath, H., Meier, T. and Mayer, C. 2003. [Loose housing system with cubicles as an alternative for finishing bulls.] In Bau, Technik und Umwelt in der landwirtschaftlichen Nutztierhaltung, pp. 405-408. KTBL, Darmstadt

Süss, M. 1994. [Housing systems for growing cattle.] KTBLArbeitsblatt 1096. http: //www.ktbl.de/ab/ab1096/ab1096.htm

Tucker, C. B., Weary, D. M. and Fraser, D. 2004. Free-stall dimensions: effects on preference and stall usage. Journal of Dairy Science 87: 1208-1216.

Veissier, I., Capdeville, J. and Delval, E. 2004. Cubicle housing systems for cattle: comfort of dairy cows depends on cubicle adjustment. Journal of Animal Science 82: 3321-3337.

Venables, W. N. and Ripley, B. D. 2002. Modern applied statistics with S, fourth edition. Springer, New York.

(Received 7 February 2005 - Accepted 27 June 2005) 